\title{
The Effects of the Structure-Foundation Interaction in the Structural Response of a TBM Gallery
}

\author{
Cisneros Felipe ${ }^{1}$, Juan Pablo Cabrera ${ }^{1}$, Juan Gabriel Barbecho ${ }^{1}$, Adrian Popovici ${ }^{2}$ and Cornel Ilinca ${ }^{2}$ \\ 1. Civil Engineering Department \& PROMAS I+D+I Research Center University of Cuenca, Ecuador \\ 2. Department of Hydrotechnics Engineering, Technical University of Civil Engineering, Bucharest 020396, Romania
}

\begin{abstract}
The effects of the interaction between a gallery lining and surrounding ground are evaluated. The gallery is circular with constant thickness and surrounding ground as geotechnical characteristics is soft one. Two types of ground are successively considered with bulk modulus $\mathrm{K}=9,260 \mathrm{kPa}$ and $\mathrm{K}=4,630 \mathrm{kPa}$. The analysis is carried out for a gallery with $3.80 \mathrm{~m}$ inner diameter and $25 \mathrm{~cm}$ thickness. This under construction is part of the irrigation system of the "Los Ríos" county (Ecuador). Comprehensive computations in various hypotheses pointed out the significant effects of the interaction. The sectional stresses $(\mathrm{M}, \mathrm{N})$ in the gallery lining embedded in soft ground depend mainly of the gallery depth versus ground surface. Contrary, the mechanical characteristics of the surrounding ground resulted to have little influence.
\end{abstract}

Key words: Circular gallery (tunnel), interaction, structural analysis, finite element method (FEM).

\section{Introduction}

A large irrigation system (Proyecto PACALORI) is under construction in "Los Ríos" Province in Ecuador (Fig. 1). The system consists of two water intakes on the rivers Calabí and Vinces-Quevedo capturing about $20+30.6=50.6 \mathrm{~m}^{3} / \mathrm{s}$ water which is transported by a network of galleries reachig to a total length of $53 \mathrm{~km}$ in 13 artificial lakes created by 13 earth dams. The total volume of reservoirs reaches $798.4 \mathrm{hm}^{3}$ ensuring irrigation during the dry season (June-December) of a potential surface of 103,876 ha [1].

This paper is referring to interection effects between a circular gallery (tunnel) and surrounding soft ground. The study is performed in the case of the gallery for water transport from Calabí river to Lechugal II reservoir (Fig. 1). The gallery is of $3.80 \mathrm{~m}$ inner diameter, has $0.25 \mathrm{~m}$ lining thickness, $3.5 \mathrm{~km}$ length and it will be built by TBM (Tunnel Boring Machine) technology. It conveys in free flowing $20 \mathrm{~m}^{3} / \mathrm{s}$ water to Lechugal II reservoir during dry season.

Corresponding author: Adrian Popovici, professor, research fields: hydraulic construction and earthquake engineering.
Geology, at regional level including the area of the gallery is made up mostly unconsolidated sediments that age corresponding to recent Quaternary deposits, and topped by volcanic ash. The geotechnical characteristics of surface materials show significant variations regarding the mechanical behavior. The geomorphological phenomena are generated by erosion and not necessarily by tectonic factors. The gallery area is considered a tectonically stable zone, free of fails and few seismic events with significant magnitude. The gallery alignment crosses a land of soft ground of different types: loose sand, rusty mud, sandy mud, sandy clay, gravels, sandstone, marl and other.

The gallery - surrounding ground interection effects are analysed in two cross sections of the gallery taking into account the linear elastic behavior for materials. The cross profiles P6 and P9 (Fig. 2) were selected from gallery route, they corresponding to minimum (14 $\mathrm{m}$ ) and maximum (30 m) ground coverage over the key of the gallery sections. The stress/strain state in gallery linning and surrounding ground are evaluated in 2D and $3 \mathrm{D}$ for different mechanical characteristics of the ground running two software, respectively Geo Studio 


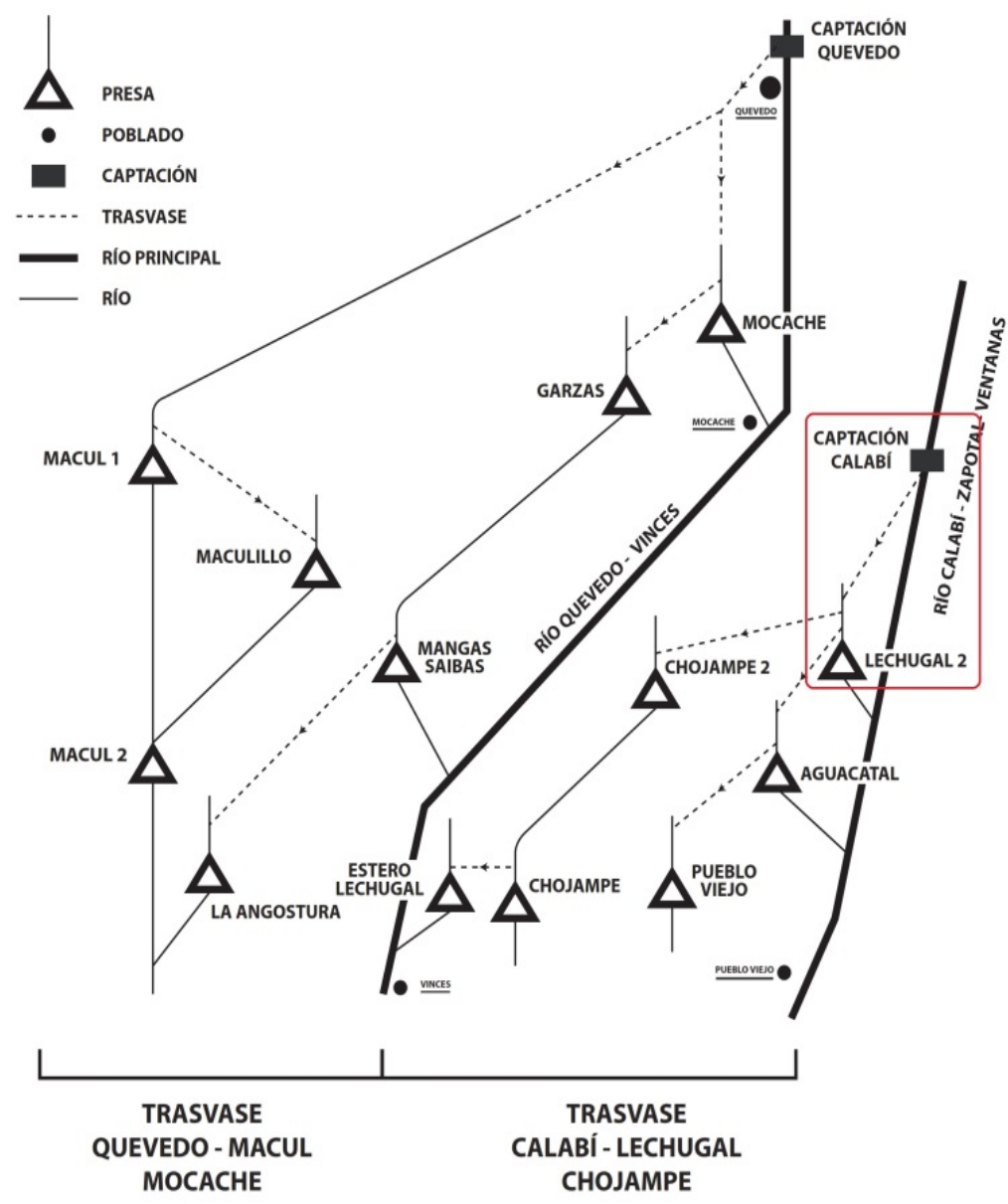

Fig. 1 Scheme of the PACALORI irrigation system from Los Rios Province (Ecuador).

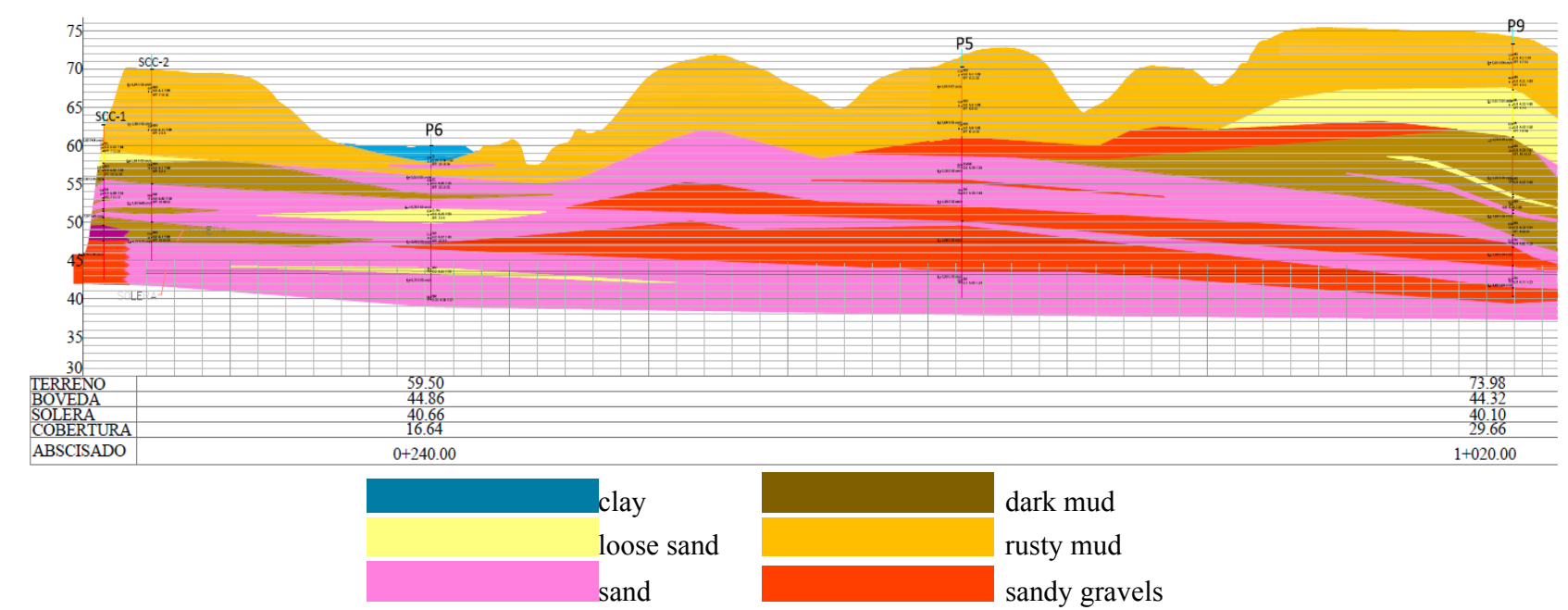

Fig. 2 Upstream route longitudinal profile through the axis of the Calabí river intake-Lechugal II reservoir gallery.

Sigma W [2] and ABAQUS [3].

\section{Calculation Procedures}

The analyses are carried out in linear elastic hypothesis for materials behavior. The gallery-surrounding ground unitary system was discretized in finite elements in both 2D (bi-dimensional) and 3D (three-dimensional) problems. 
Fig. 3 illustrates two examples of 2D and 3D meshing applied in the analyses with ABAQUS.

The material characteristics used for structural analysis of the Calabí river-Lechugal II reservoir gallery were chosen based on in-site SPT (Standard Proctor Test) and literature data, they being presented in Table 1.

In order to evaluate the effects of the interaction between gallery lining and surrounding ground two groups of values for elasticity module and Poisson coefficient, respectively $\mathrm{E}=10,000 \mathrm{kPa}, \mu=0.32$ and $\mathrm{E}=5,000 \mathrm{kPa}, \mu=0.32$ were considered for ground.

The lithostatic pressures corresponding to the gallery key level were applied as constant pressure at the ground surface, these meaning $540 \mathrm{kPa}$ for P9 profile and $252 \mathrm{kPa}$ for $\mathrm{P} 6$ profile.

In ABAQUS the finite element types for 2D mesh were quadrilaterals with 4 nodes including incompatible mode (CPS4I) for ground modeling, respectively beams (B21) for gallery lining modeling. The same types of elements were used in 2D analyses with Sigma W.

In 3D mesh with ABACUS BRICK8 elements with incompatible mode included were used for ground modeling, respectively SHELL elements for gallery lining modeling.

The type and number of elements used for meshing gallery lining-surrounding ground unitary system in various hypotheses of analysis are shown in Table 2. It may point out that elements used for gallery lining modeling (Quadrilateral, Beam, Brick, Shell) are linear ones and thus the circular shape of the gallery is approximated by a poligonal one. In these conditions it is important to use an important number of elements meshing the gallery lining perimeter.

Boundary conditions were applied to lateral and bottom edges of meshes. They consisted in blockage of the node translations on normal direction to edge surfaces and of all posible rotations.
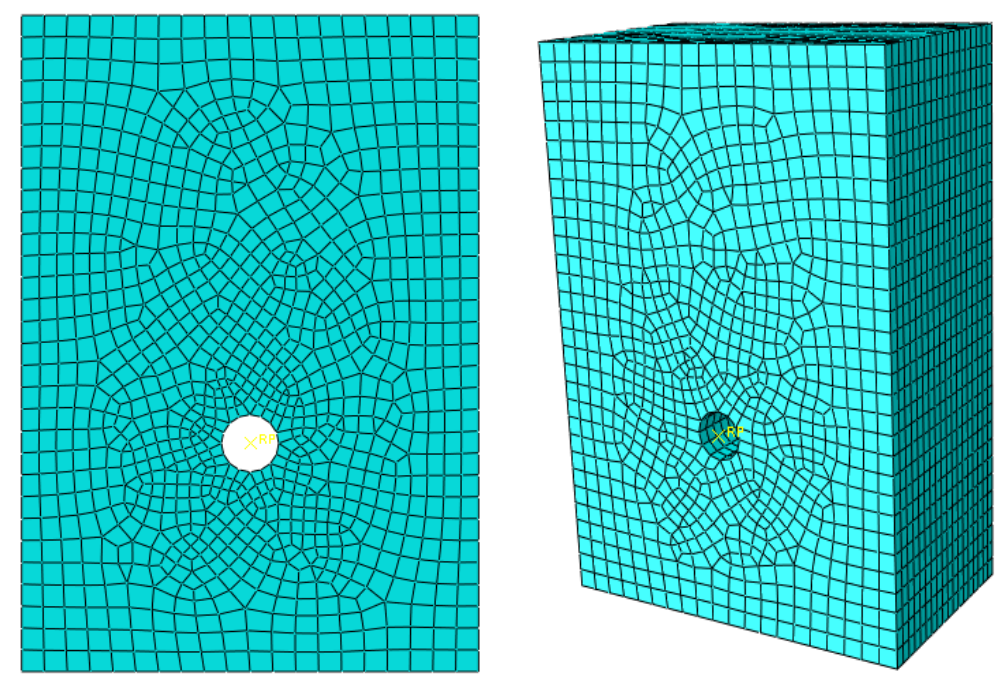

Fig. 3 Finite element meshes by ABAQUS of the gallery-surrounding ground system in 2D and 3D problems.

Table 1 Material characteristics used for structural analysis.

\begin{tabular}{lllll}
\hline Type of material & $\gamma \mathrm{kN} / \mathrm{m}^{3}$ & $\mathrm{E} \mathrm{kPa}$ & $\mu$ & $\mathrm{K} \mathrm{kPa}$ \\
\hline Concrete in gallery lining & 24 & $24,000,000$ & 0.2 & $13,000,000$ \\
Sandy clay & 18 & 6,000 & 0.35 & 6,670 \\
Mud & 18 & 6,000 & 0.35 & 6,670 \\
Gravel & 18 & 18,000 & 0.30 & 15,000 \\
Marl & 21 & 40,000 & 0.25 & 26,670 \\
Sandstone & 21 & 40,000 & 0.25 & 26,670 \\
\hline
\end{tabular}


Table 2 Type and number of finite elements.

\begin{tabular}{|c|c|c|c|c|c|c|c|}
\hline \multirow{3}{*}{$\begin{array}{l}\text { Software } \\
\text { problem type }\end{array}$} & \multirow{3}{*}{$\begin{array}{l}\text { Key gallery } \\
\text { deepness }\end{array}$} & \multicolumn{6}{|c|}{ Type and number of finite elements } \\
\hline & & \multicolumn{2}{|c|}{ Ground } & \multicolumn{4}{|c|}{ Gallery } \\
\hline & & Quadrilateral & Brick & Quadrilateral & Beam & Brick & Shell \\
\hline P9 Abaqus $3 \mathrm{D} \mathrm{Eg}=10,000 \mathrm{kPa}$ & 30 & & 12,520 & - & - & - & 240 \\
\hline P9 Abaqus $3 \mathrm{D} \mathrm{Eg}=10,000 \mathrm{kPa}$ & 30 & - & 12,520 & - & - & 240 & - \\
\hline P6 Abaqus $2 \mathrm{D} E g=10,000 \mathrm{kPa}$ & 14 & 598 & - & - & 12 & - & - \\
\hline P6 Abaqus $2 \mathrm{D} \mathrm{Eg}=5,000 \mathrm{kPa}$ & 14 & 598 & - & - & 12 & - & - \\
\hline P9 Abaqus $2 \mathrm{D} \mathrm{Eg}=10,000 \mathrm{kPa}$ & 30 & 896 & - & - & 12 & - & - \\
\hline P9 Abaqus $2 \mathrm{D} \mathrm{Eg}=5,000 \mathrm{kPa}$ & 30 & 896 & - & - & 12 & - & - \\
\hline Sigma W 2D Plane Eg $=10,000 \mathrm{kPa}$ & 14 & 13,601 & - & 1,350 & - & - & - \\
\hline Sigma W 2D Beam Eg $=10,000 \mathrm{kPa}$ & 14 & 13,601 & - & - & 270 & - & - \\
\hline Sigma W 2D Plane $\mathrm{Eg}=5,000 \mathrm{kPa}$ & 14 & 13,601 & - & 1,350 & - & - & - \\
\hline Sigma W 2D Beam Eg $=5,000 \mathrm{kPa}$ & 14 & 13,601 & - & - & 270 & - & - \\
\hline Sigma W 2D Plane Eg $=10,000 \mathrm{kPa}$ & 30 & 14,774 & - & 1,350 & - & - & - \\
\hline Sigma W 2D Beam Eg $=10,000 \mathrm{kPa}$ & 30 & 14,774 & - & - & 270 & - & - \\
\hline Sigma W 2D Plane $\mathrm{Eg}=5,000 \mathrm{kPa}$ & 30 & 14,774 & - & 1,350 & - & - & - \\
\hline Sigma W 2D Beam Eg $=5,000 \mathrm{kPa}$ & 30 & 14,774 & - & - & 270 & - & - \\
\hline
\end{tabular}
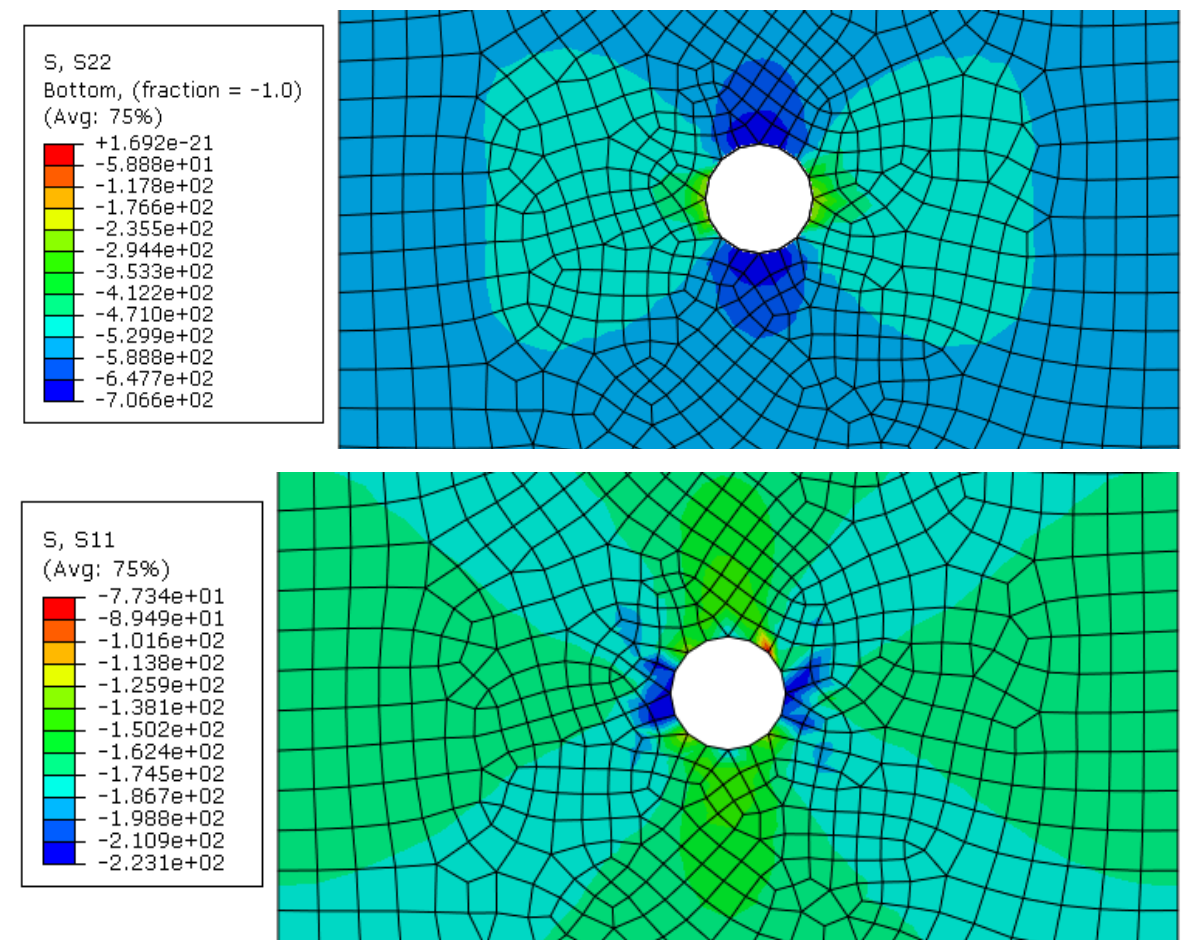

Fig. 4 Contour lines of $\sigma_{\mathrm{v}}(\mathrm{S} 22)$ and $\sigma_{\mathrm{h}}(\mathrm{S} 11)$ stresses in ground around gallery lining (ABAQUS, $2 \mathrm{D}, \mathrm{K}=9260 \mathrm{kPa}$, Beam modeling gallery lining).

\section{Results in Analyses}

Some significant results obtained in the analyses carried out are presented in the followings 4 to 10 figures.

Fig. 4 points out that gallery lining being much more stiffer than the surrounding ground attract loads from outside sector of the vertical planes tangent to gallery abutments. The loads attracted are directly proportional to the ratio $\mathrm{E}_{\mathrm{c} \text {, gallery lining }} / \mathrm{E}_{\mathrm{g}, \text { ground }}$.

Fig. 5 confirms that $\tau_{x y}$ (S12) (shear stresses) in vertical planes tangent to gallery abutments are downward on the face of the sector over gallery. They are diminishing in elevation and reach 0 at about $6 \mathrm{~m}$ 
over key gallery level for $30 \mathrm{~m}$ gallery depth versus ground surface.

The contour lines of vertical stresses $\sigma_{v}(S 22)$ in ground computed in 3D analysis (Fig. 6) have similar shapes with those resulted from $2 \mathrm{D}$ analysis.

The vertical stresses $\sigma_{v}(S 22)$ and horizontal stresses $\sigma_{h}(S 11)$ in gallery lining meshed with Brick elements processed as sectional stresses $(\mathrm{M}, \mathrm{N})$ led to simlar diagrams with the case of gallery lining meshed with Shell elements. However, last case leds to a more flexible structure with significant effect on bending moment value $\mathrm{M}$ at gallery abutments (see Table 3).
Fig. 8 illustrates contour lines of the horizontal stresses $\sigma_{h}$ (S33) on longitudinal direction of the gallery. The stresses are 4-5 times less than $\sigma_{v}(S 22) \sigma_{h}$ (S11) in the cross section of the gallery.

Fig. 9 presents diagrams of the vertical stresses $\sigma_{v}$ (S22) in a horizontal section, tangent to gallery key. It may remark the increase of stresses above gallery cross section because of its higher relative stiffness versus surrounding ground.

As is expected the reduction of the ratio $E_{c}$, gallery lining $/ \mathrm{E}_{\mathrm{g}}$, ground led to some reduction of the bending moments at the gallery key. Contrary the variation of the axial forces is unsignificant one (Fig. 10).

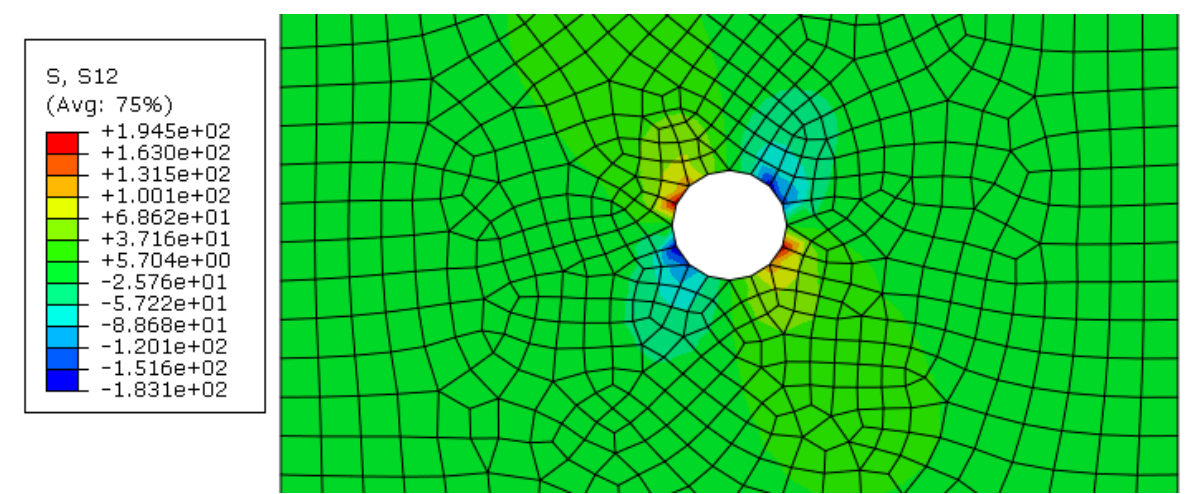

Fig. 5 Contour lines of $\tau_{\mathrm{xy}}$ (S12) stresses in ground around gallery lining (ABAQUS, 2D, K = 9,260 kPa, Beam modeling gallery lining).
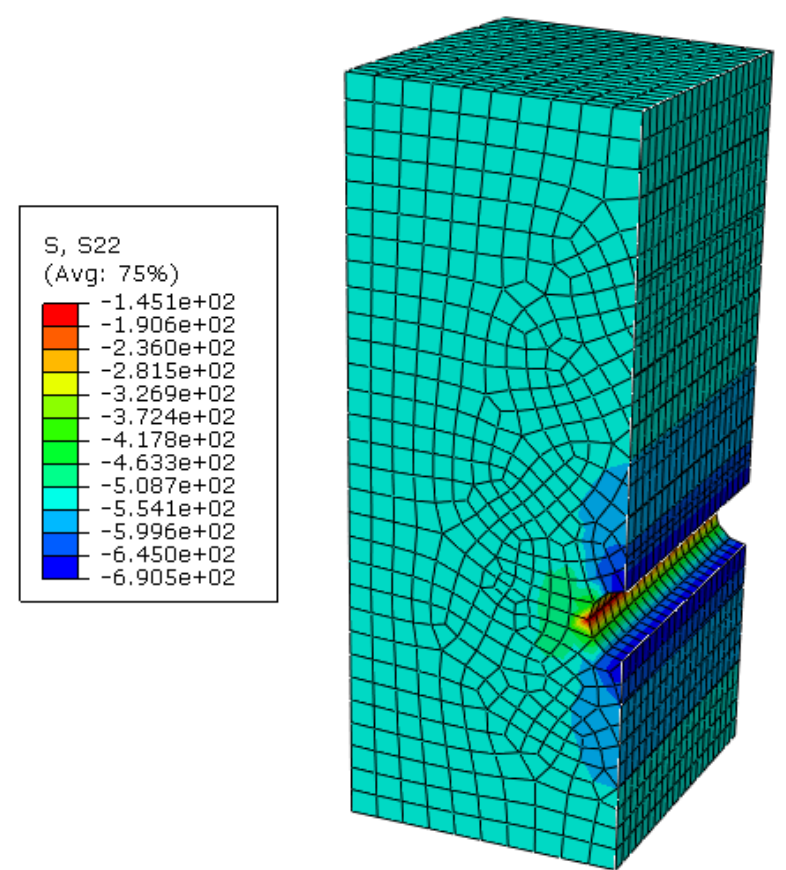

Fig. 6 Contour lines of $\sigma_{\mathrm{v}}(\mathrm{S} 22)$ stresses in ground surrounding gallery lining (ABAQUS, 3D, $\mathrm{K}=9,260 \mathrm{kPa}$, Shell modeling gallery lining). 

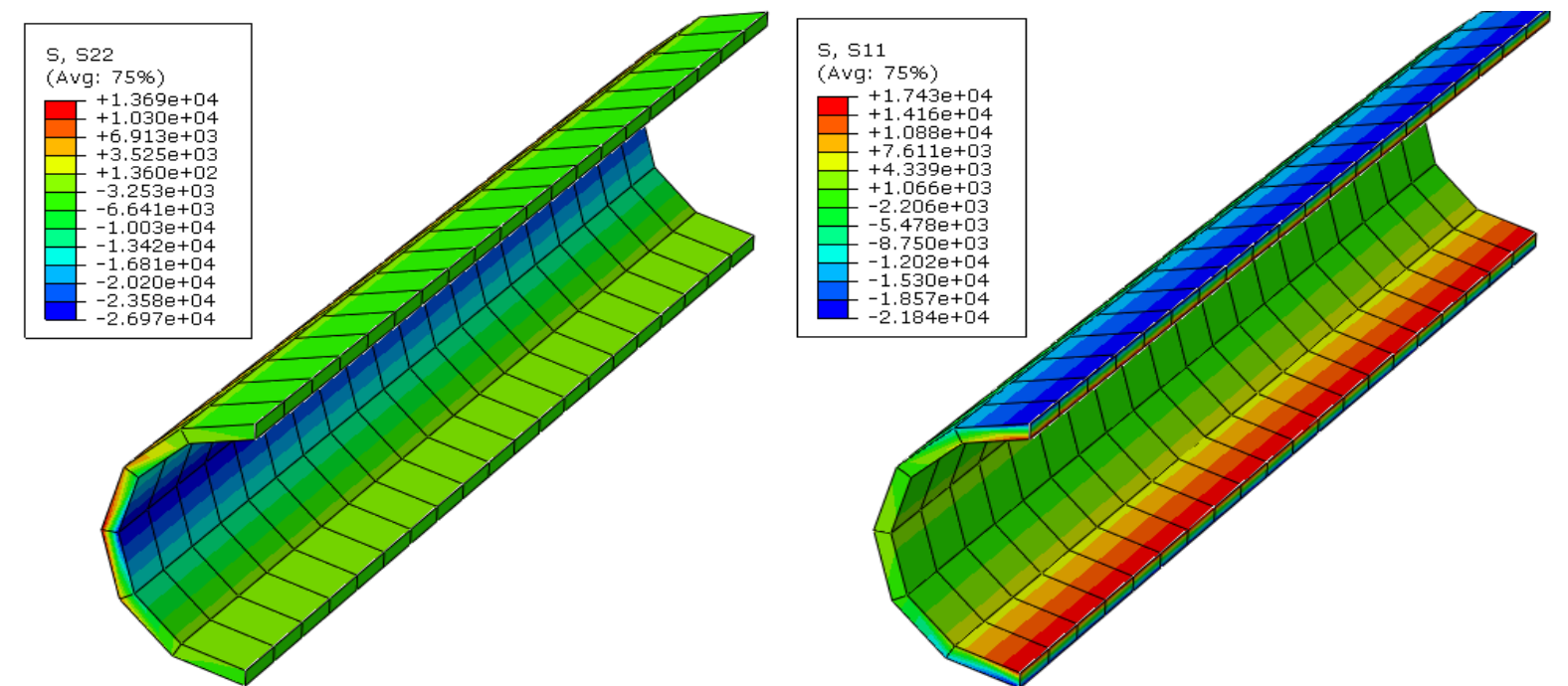

Fig. 7 Contour lines of $\sigma_{\mathrm{v}}(\mathrm{S} 22)$ and $\sigma_{\mathrm{h}}(\mathrm{S} 11)$ stresses in gallery lining (ABAQUS, 3D, $\mathrm{K}=9,260 \mathrm{kPa}$, Brick8 modeling gallery lining).

Table 3 Values of sectional stresses in the galery linning.

\begin{tabular}{|c|c|c|c|c|c|c|c|c|}
\hline \multirow{2}{*}{$\begin{array}{l}\text { Calculus method } \\
\text { Software problem type }\end{array}$} & \multicolumn{2}{|c|}{ Element type } & \multicolumn{3}{|c|}{$\mathrm{M}[\mathrm{kNm}]$} & \multicolumn{3}{|c|}{$\mathrm{N}[\mathrm{kN}]$} \\
\hline & Ground & Gallery & Key & Abutment & Apron axis & Key & Abutment & Apron axis \\
\hline $\begin{array}{l}\text { Historical stresses method } \\
\text { without interaction } \mathrm{P} 9, \mathrm{H}=30 \mathrm{~m}\end{array}$ & - & - & 451 & 406 & 405 & 328 & 1,093 & 794 \\
\hline $\begin{array}{l}\text { Abaqus 3D } \\
\mathrm{P} 9, \mathrm{H}=30 \mathrm{~m} \mathrm{Eg}=10,000 \mathrm{kPa}\end{array}$ & Brick & Shell & 197 & 477 & 197 & 702 & 1,590 & 702 \\
\hline $\begin{array}{l}\text { Abaqus 3D } \\
\mathrm{P} 9, \mathrm{H}=30 \mathrm{~m} \mathrm{Eg}=10,000 \mathrm{kPa}\end{array}$ & Brick & Brick & 204 & 212 & 204 & 549 & 1,660 & 549 \\
\hline $\begin{array}{l}\text { Abaqus 2D } \\
\mathrm{P} 6, \mathrm{H}=14 \mathrm{~m} \mathrm{Eg}=10,000 \mathrm{kPa}\end{array}$ & Quadrilateral & Beam & 183 & 184 & 183 & 291 & 770 & 291 \\
\hline $\begin{array}{l}\text { Abaqus 2D } \\
\mathrm{P} 6, \mathrm{H}=14 \mathrm{~m} \mathrm{Eg}=5,000 \mathrm{kPa}\end{array}$ & Quadrilateral & Beam & 202 & 203 & 202 & 287 & 776 & 287 \\
\hline $\begin{array}{l}\text { Abaqus 2D } \\
\mathrm{P9}, \mathrm{H}=30 \mathrm{~m} \mathrm{Eg}=10,000 \mathrm{kPa}\end{array}$ & Quadrilateral & Beam & 442 & 442 & 442 & 610 & 1,683 & 610 \\
\hline $\begin{array}{l}\text { Abaqus 2D } \\
\mathrm{P} 9, \mathrm{H}=30 \mathrm{~m} \mathrm{Eg}=5,000 \mathrm{kPa}\end{array}$ & Quadrilateral & Beam & 474 & 474 & 474 & 611 & 1,670 & 611 \\
\hline $\begin{array}{l}\text { Sigma W 2D } \\
\mathrm{P} 6, \mathrm{H}=14 \mathrm{~m} \mathrm{Eg}=10,000 \mathrm{kPa}\end{array}$ & Quadrilateral & Plane & 92 & 102 & 90.4 & 306 & 688.4 & 280.4 \\
\hline $\begin{array}{l}\text { Sigma W 2D } \\
\mathrm{P} 6, \mathrm{H}=14 \mathrm{~m} \mathrm{Eg}=10,000 \mathrm{kPa}\end{array}$ & Quadrilateral & Beam & 134.5 & 137.5 & 135.7 & 273.6 & 600.8 & 324.8 \\
\hline $\begin{array}{l}\text { Sigma W 2D } \\
\mathrm{P} 6, \mathrm{H}=14 \mathrm{~m} \mathrm{Eg}=5,000 \mathrm{kPa}\end{array}$ & Quadrilateral & Plane & 92 & 111.4 & 99.7 & 306 & 703.9 & 266.5 \\
\hline $\begin{array}{l}\text { Sigma W 2D } \\
\mathrm{P} 6, \mathrm{H}=14 \mathrm{~m} \mathrm{Eg}=5,000 \mathrm{kPa}\end{array}$ & Quadrilateral & Beam & 141.5 & 145.2 & 151.8 & 307.4 & 704 & 320.9 \\
\hline $\begin{array}{l}\text { Sigma W 2D } \\
\mathrm{P9}, \mathrm{H}=30 \mathrm{~m} \mathrm{Eg}=10,000 \mathrm{kPa}\end{array}$ & Quadrilateral & Plane & 192.2 & 198.4 & 181.2 & 700.4 & $1,363.9$ & 636.6 \\
\hline $\begin{array}{l}\text { Sigma W 2D } \\
\mathrm{P} 9, \mathrm{H}=30 \mathrm{~m} \mathrm{Eg}=10,000 \mathrm{kPa}\end{array}$ & Quadrilateral & Beam & 272.4 & 278.3 & 275.7 & 575 & $1,209.4$ & 625.8 \\
\hline $\begin{array}{l}\text { Sigma W 2D } \\
\mathrm{P} 9, \mathrm{H}=30 \mathrm{~m} \mathrm{Eg}=5,000 \mathrm{kPa}\end{array}$ & Quadrilateral & Plane & 213.3 & 219.2 & 200.5 & 707.1 & 1,385 & 607.5 \\
\hline $\begin{array}{l}\text { Sigma W 2D } \\
\mathrm{P} 9, \mathrm{H}=30 \mathrm{~m} \mathrm{Eg}=5,000 \mathrm{kPa}\end{array}$ & Quadrilateral & Beam & 308 & 311.2 & 304 & 566 & 1,219 & 617.6 \\
\hline
\end{tabular}




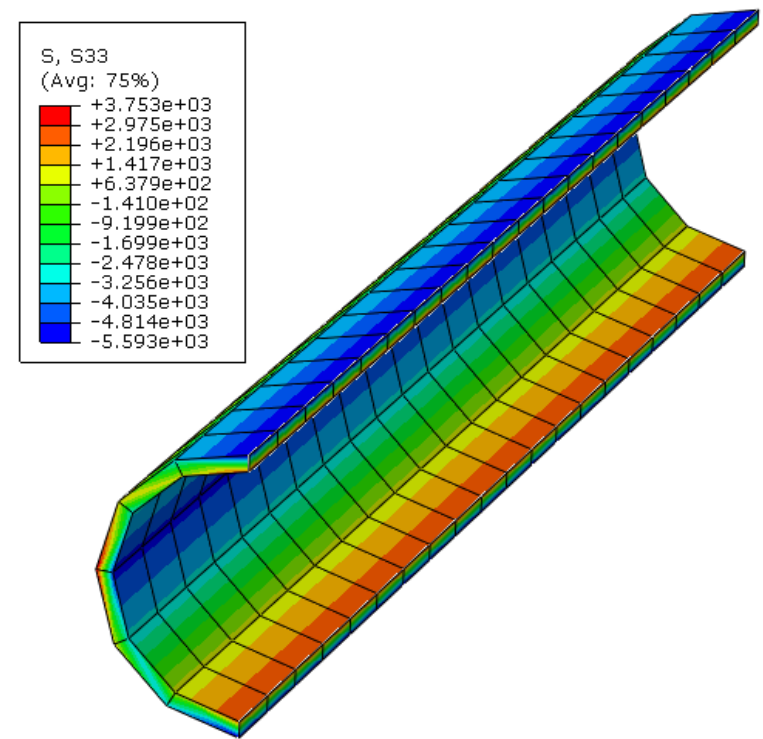

Fig. 8 Contour lines of $\sigma_{\mathrm{h}}(\mathrm{S33})$ stresses in gallery lining on longitudinal direction (ABAQUS, 3D, K $=9,260 \mathrm{kPa}$, Brick8 modeling gallery lining).
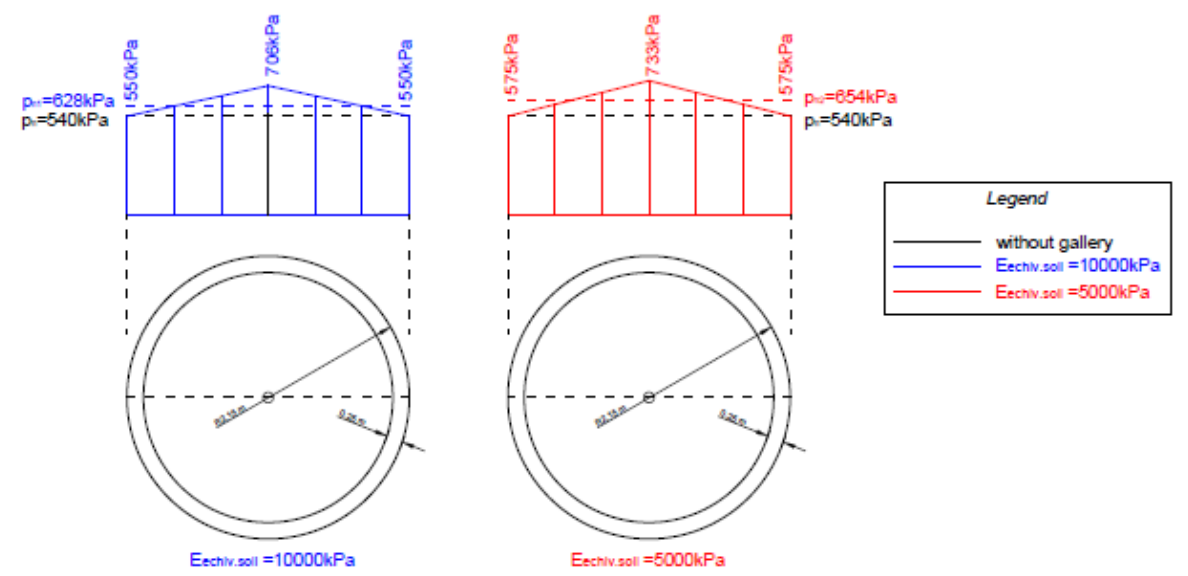

Fig. 9 Vertical $\sigma_{v}(\mathrm{~S} 22)$ diagram stresses in ground on horizontal section at gallery key level for various $\mathrm{E}_{\text {ground }}$ (ABAQUS, 2D, Beam modeling gallery lining).
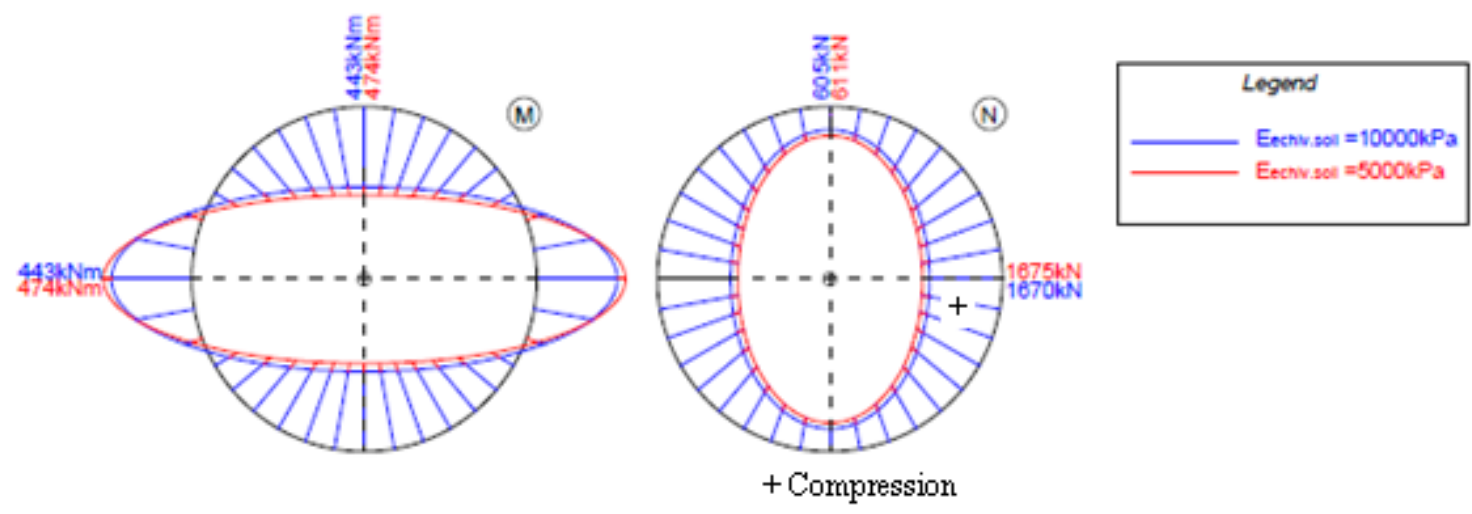

Fig. 10 Sectional stresses (M, N) diagrams in gallery lining for various $\mathbf{E}_{\text {ground }}$ (ABAQUS, 2D, Beam modeling gallery lining).

In Table 3, it is centralized presented the values of sectional stresses $(\mathrm{M}, \mathrm{N})$ in the gallery linning for all mesh variants considered in this study. For initial, it may remark from Table 2 that meshes run in ABAQUS 
were coarse ones, while the meshes run in Sigma W were refined ones. A coarse mesh led to a higher stiffness of the gallery structure with important effects on $\mathrm{M}$ values. Refined meshes run in Sigma $\mathrm{W}$ led up to $50 \%$ reduction of the equivalent $\mathrm{M}$ computed by coarse mesh run with ABAQUS.

All variants run emphasized that sectional stresses $(\mathrm{M}, \mathrm{N})$ and of course and other output parameters (strains, displacements, unitary stresses) have a linear variation function of the gallery depth versus ground surface.

The discretization with Beam elements of the gallery lining led always to higher values $M$ versus their equivalents computed using Quadrilateral (Plane) meshing gallery lining. The differences reach to $40 \%$ for bending moments $\mathrm{M}$ and to $15 \%$ for axial forces $\mathrm{N}$.

$3 \mathrm{D}$ coarse meshes run in ABAQUS allowed three-dimensional degrees of freedom for node displacements and the resulting values for $\mathrm{M}, \mathrm{N}$ have become closer to their equivalents computed in refinated 2D meshes run in Sigma W.

\section{Concluding Remarks}

The following concluding remarks can be formulated based on the result of the study:

- The stress states $(\mathrm{M}, \mathrm{N})$ in the galleries (tunnels) lining embeded in soft ground mainly depend of the underground structure deepness versus ground surface. The sectional stresses $(\mathrm{M}, \mathrm{N})$ have a linear variation function of the gallery depth versus ground surface. The mechanical characteristics of the ground layers surrounding the gallery have generally unsignificant influence. For instance a variation of $100 \%$ of the ground characteristics $(5,000 \mathrm{kPa}$ and $10,000 \mathrm{kPa})$ generated a variation of only $9 \%$ of the bending moments (M) in the gallery lining. Moreover the axial forces have varied even less, respectively $1.5 \%$. This result is different from the gallery built in hard ground (rocks) where above the gallery are born discharge vaults that depend of the mechanical characteristics of rocks and not of the gallery depth versus ground surface [4].

- Generally, the influence of the interaction between gallery structure and surrounding ground is an important one. The equivalent sectional stresses (M, N) in gallery lining without interaction are higer. Taking into account this interaction, the bending moments (M) in gallery lining in cases of refinated meshes are reduced with about $50 \%$ versus their equivalent in neglecting interaction case.

- The bending moments in the gallery lining are sensitive with finesse (refinament) of the finite element mesh, element types, boundary conditions. Contrary, the axial forces are less sensitive. A coarse mesh led to a stiffer structure.

\section{Acknowledgements}

The authors express their gratitude to the authorities of the Secretary of Water (SENAGUA) and the Empresa Publica del Agua (EPA EP) Ecuadorian entities of water issues in charge, for permission through PROMAS University of Cuenca to use in this paper some data from Pacalori project whose ownership belongs to these institutions.

\section{References}

[1] Proyecto PACALORI. 2013. "Plan de aprovachamento y control del agua en la provincial de Los Rios. Estudio de prefactabilidad (in Spanish)." Universidad de Cuenca, Ecuador.

[2] Geo Studio Sigma W. 2007. GEO SLOPE International Ltd., Calgari-Alberta, T2P 2Y5 Canada.

[3] Abaqus 6.11/CAE Users Manual. 2009. United States of America: Abaqus Inc.

[4] Priscu, R. 1974. Construcții Hidrotehnice-Volumul 2 (in Romanian). Editura Didactică și Pedagogică, Bucharest. 